\title{
FOMENTANDO A EDUCAÇÃO NÃO FORMAL NO LAZER E RECREAÇÃO EM HOTEIS
}

Recebido em: 07/11/2014

Aceito em: 10/08/2015

\author{
Marcio Aparecido Franco de Godoy Fazolin ${ }^{1}$ \\ Universidade Paulista \\ Limeira - SP - Brasil \\ Luciano Allegretti Mercadante ${ }^{2}$ \\ Universidade Estadual de Campinas \\ Limeira - SP - Brasil \\ Regina Célia Grando ${ }^{3}$ \\ Universidade Federal de São Carlos \\ São Carlos - SP - Brasil
}

RESUMO: O lazer e a recreação assumem diferentes classificações e múltiplas abordagens em relação ao tempo livre da sociedade. O presente estudo apresenta uma discussão sobre a dimensão educacional relacionada às atividades de lazer e recreação em hotéis, a partir de uma pesquisa de campo realizada com hospedes e profissionais da área hoteleira. $\mathrm{O}$ objetivo do estudo foi investigar em que medida as atividades de lazer e recreação realizadas em hotéis contribuem para formação integral de crianças entre 06 e 14 anos. Com uma revisão sistemática da literatura, foi realizada uma pesquisa qualitativa do diário de campo. Foi realizada uma observação das atividades do hotel em três dias da programação de lazer. Após a fase de observação, a análise aconteceu com base em quatro categorias; (1) cultura corporal do movimento; (2) jogo simbólico e ação cognitiva; (3) a competição como sociabilização; (4) educação não formal e potencial motor. Essas categorias demonstraram um processo educativo que contribui para a formação integral daqueles que praticam as atividades em um ambiente de educação não formal. A investigação realizada demonstrou que existe um processo de aprendizagem durante as atividades de lazer programadas em hotéis.

PALAVRAS CHAVE: Atividades de Lazer. Hotel. Educação Não Formal.

\section{PROMOTING A NON-FORMAL EDUCATION IN LEISURE AND RECREATION IN HOTELS}

\footnotetext{
${ }^{1}$ Professor Ms. No Curso de Educação Física da Universidade Paulista, Limeira - SP.

${ }^{2}$ Professor Dr. no Curso de Ciências do Esporte, nas Faculdades de Ciências do Esporte da Universidade Estadual de Campinas.

${ }^{3}$ Professora Dra. No Curso de Matemática da Universidade São Francisco, Itatiba - SP.
} 
ABSTRACT: The leisure and recreation take different classifications and multiple approaches to leisure society. This paper presents a discussion of the educational dimension related to leisure and recreation activities in hotels, from a field survey of guests and professionals from the hotel area. The objective of this study was to investigate to what extent the leisure and recreation activities in hotels contribute to the integral formation of children from 06 to 14 years. With a systematic review of the literature, a qualitative survey was conducted, the daily field type. A note of the hotel's activities in three days of leisure program was held. After the observation phase, the analysis took place based on four categories; (1) body culture movement; (2) symbolic play and cognitive action; (3) competition and socialization; (4) non-formal education and motor potential. These categories showed an educational process that contributes to the integral formation of those who practice the activities in a non-formal education environment. The investigation demonstrated that there is a learning process for the leisure activities scheduled in hotels.

KEYWORDS: Leisure Activities. Hotel. Not Formal Education.

\section{Introdução}

O interesse principal para a elaboração deste projeto foi demonstrar a existência de uma temática educativa no ambiente não formal, preestabelecido aqui como um hotel. Deste modo pretende-se expor as características do lazer e recreação em hotéis, relacionando estas características ao contexto educacional, buscando evidenciar suas possibilidades e potencialidades em relação à educação integral de crianças entre seis e catorze anos de idade, durante a programação de lazer infantil. Estabelecem-se, no presente pesquisa, as relações entre lazer e educação apresentadas por diferentes autores, Marcellino (2002), Werneck e Isayama (2003), Camargo (1992; 1998), Waichman (1997), Gomes (2004) e outros.

Devido à abordagem específica do lazer no campo hoteleiro, o presente artigo promove uma abordagem sobre as organizações de lazer e suas relações com a educação, sobretudo não formal. Nesse contexto, Requixa (1977) aponta para um variado numero de instituições preocupadas com o oferecimento de atividades e espaços de lazer e que o crescimento da área vem desde a década de 1970 nos âmbitos federais, 
estaduais e municipais. Algumas associações que promovem programações e espaços de lazer são públicas e mantidas pelo governo, sem fins lucrativos. Outras são privadas com objetivo de lucratividade como cinemas, clubes, academias, hotéis e ainda, algumas são relacionadas ao terceiro setor, que são privadas, mas não buscam a lucratividade. A escola, sendo um equipamento não específico do lazer, não abarcará de maneira enfática em nosso estudo (CAMARGO, 1992, 1998; WERNECK; STOPPA E ISAYAMA, et al, 2001).

Inicialmente foram realizadas abordagens de conceitos também importantes, como lazer, recreação, tempo livre e a inter-relação entre os termos e sua abrangência educativa para compreensão deste estudo. Devido a uma proposta participativa e de uma atitude autônoma dos participantes no tempo de lazer neste estudo, o "ócio" considerado como uma forma lúdica de "nada a fazer" por Cavallari e Zacharias (2005), mesmo sendo uma opção de lazer muito evidente na hotelaria, não é uma abordagem enfatizada, pelo fato da pesquisa proceder a uma análise diante de uma educação não formal, caracterizada com atividades e conteúdos programados, onde, as pessoas de maneira voluntária participam da programação proposta.

Assim, esta pesquisa busca investigar em que medida as atividades de lazer e recreação realizadas em hotéis contribuem para formação integral de crianças entre 06 e 14 anos.

Para tanto, propõe-se:

1. Identificar uma dimensão educacional relacionada às atividades de lazer e recreação em hotéis.

2. Discutir uma proposta educativa na programação de lazer em hotéis para a formação integral dos indivíduos inseridos neste contexto. 


\section{Especificidades do Lazer}

O lazer é um tema que abrange diferentes classificações e que promove múltiplas abordagens, como por exemplo, lazer e sociedade, lazer e trabalho, tempo e lazer, lúdico e lazer. A discussão sobre o lazer enfatiza duas vertentes classificadas por Marcellino (2002) em seu estudo como, "tempo e atitude", promovendo a compreensão do lazer de maneira voluntária, positiva e dinâmica para a prática de uma atividade desenvolvida. Junto a esta relação, tempo/atitude acontece um sentido educativo do lazer, sendo que, em seu tempo livre o indivíduo busca uma vivência individual e voluntária de ações pelas quais a aprendizagem ocorre de maneira lúdica.

Dentre as definições que detém o lazer, uma das concepções proposta por segundo Requixa (1977), é apontada como uma ocupação não obrigatória, de livre escolha do indivíduo que a vivencia e cujos valores propiciam condições de recuperação auto superação e de desenvolvimento pessoal e social. Neste sentido o autor relaciona a importância do lazer em estabelecer uma aprendizagem, seja, intelectual, coletivo, moral ou social, fortalecendo a relação entre os aspectos educacionais do lazer. Nas ideias de Requixa (1980), nota-se a importância dos aspectos socioculturais, bem como, a ação voluntária e vivenciada no lazer pelo indivíduo. Caracteriza-se a possibilidade de experiências, sobretudo educativas, onde discorrem possibilidades de aprendizagem em busca de um desenvolvimento social das pessoas, por meio do lazer que pode ser conduzido de forma pedagógica.

Marcellino (1987) no mesmo estudo compreende o lazer como um abrangente campo de atividades e interesses variados, entendendo-o como a cultura no maior sentido, numa concepção ampliada, tanto na vivencia prática, quanto no tempo 
disponível daquele que participa. O lazer, o aspecto atitude é destacado pelo autor como a relação entre o homem e a vivência de qualquer atividade que promova o lazer e a satisfação do mesmo. Neste aspecto, esta promoção do lazer é desempenhada de maneira individual e voluntária em diferentes ações que proporcionem o prazer do homem em seu tempo livre (MARCELLINO, 2002; DUMAZEDIER, 1976; REQUIXA, 1974, 1980).

Nas discussões que abarcam o lazer e o tempo livre, esta se precede como a forma maior de busca pela ocupação no tempo disponível para diversão, repouso, autodesenvolvimento, seja pela leitura ou por meio da conversa, esporte etc. O que coloca o lazer como uma agente que fomenta a aprendizagem e promotor de um caráter educativo (MARCELLINO, 1997; CAMARGO, 1998).

Cavallari e Zacharias (2005) destacam "tempo livre" como todo o tempo de um indivíduo livre do tempo de trabalho e obrigações fundamentais. É aquele período designado às próprias pessoas, sem um objetivo normativo da conduta social, é o momento onde as pessoas buscam o prazer e a satisfação. Para os autores, tempo livre é considerado como "[...] o tempo total de uma pessoa, extraindo-se o tempo de trabalho e o tempo de necessidades básicas vitais, o que resta é o tempo livre” (p. 14).

Quando se fala de lúdico há uma associação a um contexto recreativo, onde o sujeito, temporariamente, relaxa esquece seus problemas sociais e frustrações, deixando fruir suas emoções e sentimentos, devido ao caráter lúdico que vivencia. Dessa forma, Werneck e Isayama (2003) pressupõe que essa ludicidade, mesmo que não se possa obter um resultado pessoalmente favorável, a sensação deve ser de que a vivência valeu a pena, mantenho a vontade de repeti-la e de conquistar novos desafios. Nesse sentido, a importância do lúdico e a vivência proposta em uma atividade ou ação vivida com 
prazer são muito mais relevantes. O resultado atingido de forma lúdica é construído sob influencia de aspectos culturais e sociais, e por isso é instável de acordo com cada grupo social em diferentes contextos e épocas (WERNECK; ISAYAMA, 2003; FERREIRA, 2003).

Na perspectiva de Marcellino (2002) e outros autores como Camargo (1998), Werneck e Isayama (2003), Waichman (1997), empenhados nos estudos do lazer e recreação com a finalidade em aproximar esta temática da área da educação, adotam um duplo sentido do lazer, balizado em duas constatações. Primeiramente, profere que o lazer, assim como a recreação é um veículo privilegiado da educação. A segunda se refere à prática das atividades de lazer como necessidade do aprendizado, estimulando seus conteúdos culturais a passarem por uma aprendizagem gradativa, promovendo um aspecto crítico e criativo dos indivíduos na ação.

Diante de uma perspectiva de que o lazer faz parte do contexto educacional, Marcellino (2002) destaca um duplo processo do lazer, como veículo e como objeto de educação, com possibilidades do desenvolvimento social e pessoal, envolvendo a educação e a vida social do homem. Sendo assim, entende-se que não é possível compreender o lazer, isolando-o de outras esferas sociais, uma vez que é parte de um processo que influencia e é influenciado por outras áreas de atuação. O que torna o lazer um fenômeno dinâmico (MARCELLINO, 2002).

Dumazedier (1980) classifica seis diferentes áreas específicas do lazer, em interesses artísticos, intelectuais, físicos, manuais, turísticos e sociais. O caráter artístico do lazer trata-se das emoções e sentimentos dos envolvidos no meio, com conteúdo estético em busca do simbólico e encantamento, envolvendo todas as manifestações 
artísticas. O interesse intelectual do lazer é aquele que anseia de explicações racionais e objetivas em busca do real, sendo relevante à experiência vivida.

As atividades físicas, esportivas, lúdicas ou qualquer ação envolvendo o movimento e habilidades motoras, são constituídas pelos interesses físicos. Já, a capacidade de manipulação de origami, artesanato, de transformação de objetos e ações que lidem com a natureza e cuidados com animais, constitui o campo dos interesses manuais. Os interesses turísticos compõem a quebra de rotina temporal e espacial, em busca de novas culturas e costumes, exemplificados pelas viagens (DUMAZEDIER, 1980).

O último interesse do lazer é o social, buscando novos contatos, relacionamentos, o convívio social. São as relações existentes em sociedade, sejam afetivas, morais ou sociais. Nesta descrição, o autor inter-relaciona lazer educação e suas facetas lúdicas e pedagógicas, destacando a recreação, o jogo e a brincadeira que como componentes capazes de contribuir no contexto educacional de maneira livre e divertida (DUMAZEDIER, 1980). Isso faz com que o mesmo indivíduo transcorra por um processo de aprendizagem lúdica, muitas vezes de maneira simbólica, onde o mundo da imaginação é parte do contexto educacional.

\section{Hotel e o Lazer Programado}

Hoje é comum pessoas de toda parte se deslocarem para outros refúgios em busca de descanso, tranquilidade, diversão e lazer. Por isto, é importante demonstrar os espaços que promovem as programações de lazer. Estas podem ser formais, como escolas e aqueles considerados não formais evidenciados como clubes, acampamentos, hotéis, teatros e outros. Os equipamentos não formais promovem o lazer da sociedade e 
intensificam-se por uma grande procura, oferecendo opções de atividades e exercícios físicos, no desporto, recreação ou bem-estar de seus usuários (CAMARGO, 1992, 1998; WERNECK; STOPPA E ISAYAMA, 2001).

O intuito em fracionar o tempo livre desperta nas pessoas, grupos e principalmente em famílias, o interesse pelos hotéis, pois, nesse ambiente são desenvolvidas diversas atividades de lazer e recreação para diferentes pessoas e idades. Diante desta preocupação dos turistas, os hotéis, sejam de praia, de campo, estância, spas, resort ou hotéis localizados em selvas, conhecidos como lodges, estão proporcionando alternativas para o lazer de seus visitantes (CAVALLARI e ZACHARIAS, 2005). Contudo, é importante esclarecer que as opções de atividades que um hotel oferece dependem de sua estrutura física e de objetivos diferenciados para a realização das atividades desenvolvidas. Pensando na estrutura hoteleira, Negrine; Bradcz e Carvalho (2001, p. 66) evidenciam algumas informações necessárias para a elaboração das atividades de lazer e recreação neste setor:

[...] em primeiro lugar devem-se ter informações pertinentes à estrutura física de que se dispõe para implantar o serviço. Em segundo lugar, ter certeza quanto aos objetivos do proprietário do hotel ou da rede hoteleira ao proporcionar esse tipo de serviço. Em terceiro lugar, o planejador deve obter informações junto à administração do hotel o perfil geral de hóspedes.

Para os autores, estas são as informações necessárias para realizar um desenho do projeto que objetive a implantação do serviço do lazer, por meio de uma programação correspondente à faixa etária e ao perfil do usuário inserido. Define-se uma programação de lazer, correspondendo a toda atividade realizada em hotéis ou outra entidade. Esta programação geralmente é diferenciada pelas faixas etárias inseridas no hotel, ou para um grupo de congressistas, por exemplo, e é dividida por horários e objetivos comuns, de acordo com a necessidade de cada perfil. A 
programação de lazer deve ser flexível e acessível aos diferentes grupos ou faixas etárias, podendo estes variar conforme as datas comemorativas. Ainda Negrine; Bradcz e Carvalho (2001, p. 49) a programação de lazer pode incluir como finalidade:

1. Informar aos hóspedes as alternativas de lazer e recreação que o hotel oferece; 1. Buscar participação livre e espontânea dos hóspedes nas atividades oferecidas; 2. Facilitar e ampliar a comunicação entre as pessoas; 3. Criar um clima lúdico, descompromissado de juízos de valor, sem discriminação de idade, sexo ou raça; 4. Permitir uma avaliação permanente dos serviços oferecidos.

Para os autores a programação de lazer é capaz de oportunizar aos hóspedes, atividades marcadas por jogos, brincadeiras individuais e coletivas com o intuito de causar, além do entretenimento, uma integração, sobretudo uma complementação educacional sobre diversos aspectos socioculturais. Assim, esse trabalho busca demonstrar que uma programação de lazer pode desempenhar também um objetivo educacional, e que a equipe de lazer é capaz de buscar uma meta maior que um simples entretenimento aos que participam. E a programação de lazer pode, por sua vez, pode mobilizar e transformar cada um destes participantes para estabelecer uma ordem educativa neste ambiente não formal, com uma proposta que seja lúdica, entretanto, educativa, em todas as faixas etárias, visando transformar o simples monitor de hotéis em indivíduos envolvidos, transformadores e educadores de um contexto educacional não formal, deixando de promover apenas uma educação informal (WAICHMAN, 1997).

\section{A Educação Não Formal}

É fato que a escola é o principal órgão de educação, uma vez que este é o ambiente pressuposto para a aprendizagem dos princípios pedagógicos e suas características, sociais, morais, culturais, cognitivas e motoras para formação dos alunos 
como cidadãos. Este processo de desenvolvimento ocorre na escola, porém, deve ser continuado fora dela com objetivo de complementar a educação dos alunos, através de uma educação não formal, em um ambiente não formal. De acordo com Waichman (1997) a educação acontece de diferentes maneiras, podendo ser formal, informal e não formal.

A educação formal é aquela desempenhada na escola, onde a aprendizagem acontece dentro da instituição regular de ensino. A educação informal é abordada por Coombs e Prosser (1973) como um processo contínuo que acontece durante toda a vida, como um desempenho cumulativo de conhecimentos adquiridos através das experiências de cada indivíduo com o meio. Já a educação não formal, assunto de discussão deste estudo, é toda atividade desenvolvida e sistematizada por meio de um programa educativo fora de um sistema escolar formal, com intenção de promover aprendizagem aos diferentes grupos sociais. A diferença entre a educação informal e a educação não formal é que a segunda é desenvolvida através de conteúdos e programas intencionais para aprendizagem (WAICHMAN, 1997).

A educação não formal é evidenciada nas atividades educativas e de capacitação, são sistemáticas e estruturadas e possuem uma duração curta durante as atividades (PAULSTON, 1972). É uma ação fornecida por agencias que promovem mudanças concretas de conduta em populações diferenciadas e buscam a aprendizagem fora do sistema educativo formal, como as escolas, por meio de fins específicos, com respaldo de uma pessoa, grupo ou uma organização identificável. As atividades de lazer e recreação elaboradas e desenvolvidas em uma programação de lazer ordenada pode ser conteúdo de uma educação não formal. Desta forma, as atividades desenvolvidas na hotelaria através de um programa para diferentes faixas etárias, podem ser trabalhadas 
na busca de uma educação não formal para a formação integral dos indivíduos inseridos no processo (BREMBECK, 1978; PAULSTON, 1972; WAICHMAN, 1997).

Visando a recreação e os jogos, Ferreira (2003) aponta que a recreação quando desempenhada com responsabilidade pelo educador é instrumento de aprendizagem para as pessoas abarcadas, podendo ser multiplicadora de conhecimentos. Com este intuito o autor deixa clara a presença de uma educação e, independente de seus conceitos e ideias estes autores evidenciam um processo de aprendizagem, seja pelo lazer, pelo jogo, pelo lúdico ou recreação e dispostos em um ambiente não formal. Brotto (2002) por sua vez menciona que o jogo é um campo das potencialidades individuais e coletivas na perspectiva de superar crises e solucionar problemas, havendo um desenvolvimento dos aspectos pedagógicos do homem, objetivando, por conseguinte, a formação integral dos indivíduos envolvidos. Este processo educacional do jogo acontece não somente em um ambiente formal como a escola, mas em outros processos de desenvolvimento do jogo, podendo ser aplicado para a busca uma vez mais de uma educação não formal, discutida aqui como a hotelaria, assim, o jogo pode ser um conteúdo do lazer (MARCELLINO, 2002).

\section{Construindo a Investigação}

A pesquisa foi realizada em um hotel durante a programação de lazer infantil, oferecida aos hóspedes em período de férias escolares. Inicialmente foi realizada uma revisão de literatura do tipo narrativa, a qual envolve análise, avaliação e integração de uma literatura, levando frequentemente às importantes conclusões em relação aos assuntos discutidos na investigação até aquele momento, versado sobre a literatura disponível (THOMAS e NELSON, 2002). Os dados foram coletados a partir da 
observação das atividades da programação de lazer infantil. A metodologia realizada na pesquisa é do tipo qualitativa, considerada uma forma de investigação que propõe a descrição dos diversos significados e componentes da realidade e expressa os diferentes sentidos dos fenômenos sociais (MAANEN, 1979).

Para Ludke e André (1986) a pesquisa qualitativa possibilita um contato direto entre o pesquisador e a situação estudada. Enfatiza o processo em função do produto, pois o ambiente natural se constitui como fonte direta de dados e o pesquisador é o seu principal instrumento. Além disso, os autores apontam que os dados coletados são predominantemente descritivos e a analise possui uma tendência indutiva. Por meio de observação participante, o qual pesquisador se faz presente ao local do fenômeno onde naturalmente acontece.

A coleta dos dados é realizada com a observação das pessoas quando estão conversando, ouvindo, trabalhando, comendo, brincando. Um procedimento de coleta de dados na forma de observação participante é descrito pelos autores como uma estratégia que envolve não somente a direta observação, mas também todo um conjunto de técnicas metodológicas, como entrevistas e consulta a materiais, por exemplo, havendo um grande envolvimento do pesquisador na situação estudada (FIORENTINI e LORENZATO, 2006).

Foram utilizadas como instrumento de coleta de dados: (1) diário de campo a partir de observações durante as atividades realizadas pelas crianças e jovens entre seis a catorze anos de idade, aplicadas por um monitor de lazer e recreação, de modo que o pesquisador apenas observou as atividades. Estas observações contêm a descrição dos locais, dos sujeitos, dos acontecimentos mais importantes. Foram analisadas cinco atividades diferentes, obtendo um total de três dias de análise. (2) questionários 
aplicados aos hóspedes, proprietários e profissionais da recreação. Para os hóspedes foi exposto um questionário misto com perguntas abertas e fechadas (FIORENTINI e LORENZATO 2006). As questões foram aplicadas a 15 hóspedes do hotel analisado.

Para a equipe de lazer foi aplicado o questionário a monitores da empresa de lazer com 2 a 5 anos de experiência profissional com idades entre 21 e 25 anos um questionário aberto com quatro questões. Já a um proprietário foi aplicado um questionário aberto com cinco questões. As análises das atividades observadas foram realizadas de forma qualitativa. As questões de cada questionário possuem características diferentes, com objetivos específicos à sua área atuante, porém, uma questão é apresentada a todas as classes questionadas, relacionado às atividades de lazer e recreação ao contexto educacional. Estas questões possibilitaram responder quais são os objetivos das pessoas quando se integram ao lazer e a recreação em hotéis. A observação participante e os objetivos serão apresentados a seguir junto à descrição e análise da pesquisa buscando inferir os resultados. Sobre os aspectos éticos da pesquisa, na época de coleta, foi solicitada uma autorização ao responsável da empresa de recreação e ao hotel, havendo uma entrevista com os mesmos sobre as intenções da pesquisa. Todos os envolvidos hóspedes e colaboradores responsáveis, tanto pelas empresas, quanto pelas crianças receberam o termo de consentimento de livre e esclarecido e puderam acompanhar as fases de observação da programação de lazer, uma vez que as atividades ocorreram no mesmo espaço de lazer. 


\section{Descrição e Análise dos Dados Coletados}

\section{Análise da Programação de Lazer}

A análise metodológica foi desenvolvida a partir das atividades da programação de lazer realizada no hotel, que teve como enfoque para esse estudo, o objetivo das atividades, a orientação teórica para construção do programa e a sequencia das atividades desenvolvidas pelo profissional de recreação responsável. Quando questionado, o mesmo ponderou sobre o sistema padronizado da programação realizada pela empresa de lazer. A firma possui um padrão da programação de lazer, através de uma orientação teórica apostilada, onde a programação é dividida por atividades iniciais chamadas ponto de encontro, para que haja uma integração dos participantes, jogos coletivos e competitivos, como futebol, queimada, entre outros, também fazem parte da programação.

Atividades desenvolvidas em piscinas promovem uma variação do meio e são bastante desenvolvidas em hotéis. Grandes jogos e caças de origem cooperativa e simbólica também são estruturados na programação de lazer proposta pela empresa, bem como, passeios culturais, conforme exigência do hotel. Vale lembrar que existe uma flexibilidade na programação padrão, onde esta pode sofrer alterações, devido ao número de hóspedes e modificações climáticas (CAVALLARI e ZACHARIAS, 2005).

A empresa sugere duas programações elaboradas por seus coordenadores. Uma programação de sol e outra de chuva, para o caso de alterações do clima. Os coordenadores são responsáveis pela programação e estes desenvolvem de acordo com cada hotel, podendo unir as faixas etárias, como aconteceu no sistema hoteleiro analisado. A coordenadora, em discussão, respondeu que pensa a programação de lazer de uma forma globalizada, promovendo o entretenimento das crianças em conjunto, 
pois, apenas um monitor da recreação é responsável pela programação infantil e de acordo com a mesma, é por este motivo, em sua opinião que a programação é ampla e atende diferentes idades infantis. A profissional tem curso superior de Turismo, e que além da preocupação de entreter as pessoas, vê a importância de uma abordagem educativa na hotelaria.

Apesar destas diferentes formas de atividades para o lazer das idades envolvidas, os objetivos são apenas de entreter e integrar as pessoas. A intenção e o desafio é satisfazer os hóspedes em sua estada e fazer com que o mesmo retorne nas próximas férias. Porém, não há análise das importantes características educativas, como, a cooperação, socialização (aspectos culturais da sociedade), a sociabilização (integração entre os envolvidos) aspectos cognitivos e motores, diversidade cultural e a imaginação, por exemplo, atributos também desenvolvidos em um meio não formal (BROTTO, 2002; VYGOTSKY, 2001; MAGILL, 2000; WAICHMAN, 1997; BRASIL，1997; FREIRE, 1997). Quando questionados sobre a abordagem educacional do lazer, os monitores da equipe de lazer, disseram acreditar no processo e formalizaram argumentos para a abordagem em questão. Concordaram que através de discussões, as atividades propostas são educativas e podem contribuir para a aprendizagem e que uma avaliação desta referida maneira não é feita. Os monitores são condescendentes que esta temática seria consequência de uma maior satisfação das pessoas inseridas.

\section{Análise do Questionário}

Para esta análise foi realizada uma triangulação das respostas apresentadas pelos hóspedes, empresários e profissionais de recreação. O questionário aplicado ao proprietário foi do tipo aberto e continha cinco questões: A primeira questionava o 
objetivo do hotel em relação aos hospedes; a segunda se o hotel disponibilizava de uma equipe de lazer, se era contratada pelo hotel ou terceirizada e qual o objetivo do hotel com essa equipe; a terceira se tratava das exigências do hotel quanto ao perfil dos monitores da equipe de recreação contratada; a quarta questão era sobre a opinião do hotel sobre as atividades desenvolvidas pela empresa especializada, caso fosse contratada; a quinta pergunta correspondia à opinião do hotel sobre as atividades da programação de lazer ser educativas, qual a importância dessa proposta para a hotelaria. O hotel, representado pelo proprietário priorizou a satisfação do hóspede em seu tempo de estada e que as atividades de lazer e recreação devem despertar o interesse e a integração dos mesmos, sendo sim educativas e auxiliando na aprendizagem daqueles que participam, criando raízes de fidelidade.

Os hóspedes foram aplicados um questionário do tipo misto, com questões fechadas e abertas. Era um questionário com quatro questões. De um a três eram perguntas fechadas, a quarta questão era aberta. Então, a primeira questionava quantas vezes buscavam a hotelaria no seu tempo de lazer, uma, duas ou mais que duas vezes ao ano; a segunda foi sobre qual objetivo o hospede busca quando vai para o hotel, atividades de lazer e recreação, aventura, conhecer pessoas e culturas e descanso; a terceira se é importante para o hospede saber se o hotel possui uma equipe de recreação, tendo com opção de escolha, apenas para entreter, porque tenho filhos, se as atividades propostas são também educativas; a quarta pergunta, aberta, questionava sobre a opinião do hospede sobre as atividades de lazer e recreação em hotéis e se estas podem ser educativas, contribuindo na educação das pessoas envolvidas nesse contexto. Ao responderam ao questionário, os hóspedes, em seus objetivos, embora reconheçam a importância da programação de lazer promover aspectos educacionais naquele 
ambiente, procuram o hotel devido às atividades de lazer oferecidas para a comodidade própria e de seus filhos.

A equipe de lazer, por sua vez, em seus objetivos, discutiu a variação dos mesmos, pois, conforme resposta cada um da recreação, possui um objetivo em seu trabalho desenvolvido, uns para obter uma renda extra, outros para conhecer pessoas, etc. Responderam ainda sobre a programação de lazer, onde falam da importância de diversificar os conteúdos para a satisfação do hóspede. É visto que mesmo com adaptações correntes na programação e com o intuito de entreter apenas, os profissionais entendem a importância de um conteúdo educativo. Sobre o questionário, todas as questões a esquipe de recreação e lazer foram do tipo aberta. O questionário continha quatro questões. A primeira sobre os objetivos da empresa com relação ao hotel e aos hospedes; a segunda sobre o perfil dos profissionais contratados pela empresa; a terceira sobre a opinião da empresa de quem deve ser o profissional de lazer; e a quarta o que a empresa compreende sobre o lazer na hotelaria e se as atividades propostas devem possuir um caráter educativo para contribuir na formação dos indivíduos envolvidos.

É notória a variedade de objetivos, tanto para os hóspedes, como para o proprietário e monitores de recreação que apesar das diferentes finalidades junto ao lazer, responderam uma questão sobre a relação das atividades de lazer e recreação ao contexto educacional. Em unanimidade abordaram a importância da educação neste processo, devido às diferentes técnicas de fomento das atividades de lazer, como as adaptações com o meio, grupos sociais, e uma aprendizagem contínua. 


\section{Análise das Atividades Programadas}

A atividade chamada "Uma tarde no cinema" foi iniciada com 30 participantes, crianças e jovens de 6 a 14 anos. Essa atividade do período teve um caráter cultural e foi dividida em etapas com perguntas, mímicas, representações. As questões foram pertinentes a variados temas, o que pode promover uma ação cognitiva das crianças, raciocinando e discutindo sobre a questão apresentada (PIAGET, 1975; VIGOSTSKY, 2001).

Como regra do jogo, os participantes, caso não soubessem as respostas, poderiam buscar ajuda com outras pessoas do hotel num tempo determinado. Essa ação evidencia o jogo em seu aspecto motor, como força, velocidade e diversas contrações musculares desenvolvidas para ações motoras em busca da resposta (GALLAHUE E OZMUN, 2003). Interessante nesse momento foi verificar que aqueles que ajudaram na brincadeira se desvinculam momentaneamente do ócio, pois ao ajudar as crianças tornam-se integrantes participativos e voluntários da equipe (MARCELLINO, 2002).

A busca pelas respostas incentivou a integração social entre as equipes e outras pessoas do hotel. Isto fez com que a competição proposta tivesse uma conotação positiva, fazendo com que algumas crianças deixassem de ser inibidas naquele momento, devido ao caráter lúdico e competitivo da brincadeira e se sociabilizassem com outras pessoas. Destaca-se o caráter educativo da atividade desenvolvida, quando fomenta o desenvolvimento dos aspectos, cognitivo, motores e sociais, através da sociabilização das pessoas participantes, direta e indiretamente (KAMII, 1991; HUIZINGA, 1999).

Outro ponto importante foi como a liderança foi proposta pelas próprias crianças. A etapa seguinte foi a fase das mímicas, utilizando apenas movimentos, 
quando somente o corpo "fala" sem emissão de qualquer ruído, as crianças realizaram mímicas de filmes, imaginando e relembrando alguns já vistos por elas. Vygotsky (2001) fala da imaginação como um impulso criativo que permite ao sujeito reordenar os elementos extraídos da realidade em novas combinações e para ele a imaginação. Para o autor a imaginação está presente nas atividades cotidianas e expressas por diferentes ações do homem, sobretudo, no contexto lúdico. Ao iniciar a primeira mímica, uma criança, disse:

- " "nossa, como vou fazer isso?"

Um colega responde:

- “Ah, sei lá, imita um animal ou um personagem”.

Neste diálogo podemos perceber que a imaginação para realizar o movimento era a principal característica naquela atividade lúdica. Wallon (1989) descreve uma associação na teoria da Psicogenética, relacionando aspectos cognitivos e motores. Fazendo menção a essa afirmativa, Magill (2000) menciona que a imaginação e a prática cognitiva estão atribuídas ao ato motor, representado pelos movimentos mímicos da atividade proposta.

A última etapa desta primeira atividade em análise foi da representação, onde cada equipe teve que imaginar e apresentar a cena de um filme. Materiais, como cartolina, tinta, tesoura, papel crepom, foram disponibilizados para uso, o que evidencia os interesses do lazer (DUMAZEDIER, 1980). Observamos aspectos educativos no trabalho simbólico dos participantes e de quem é apenas espectador, como o desenvolvimento da imaginação se relacionando com a habilidade motora, o sentido de autonomia, liderança e opiniões para a realização de uma função específica de cada criança (PIAGET, 1975; ROCHA, 2005). Com um trabalho compartilhado de maneira 
autônoma, as crianças organizavam-se em ações manuais, assumindo seus respectivos papéis em suas respectivas equipes durante a atividade. Nesse sentido, Rocha (2005, p. 73) fala do jogo:

[...] como uma atividade lúdica que se altera qualitativamente, no que ser refere tanto nos aspectos estruturais, como as relações existentes entre eles, envolvendo modificações no papel e lugar, em importância, que estes elementos ocupam ao longo do desenvolvimento.

A autora fala da importância dos papéis representados pelas pessoas envolvidas no jogo e que estes podem assumir diferentes estruturas e lugares para o desenvolvimento deste. Assim, ouviu-se:

- "Eu faço as maquiagens"

- "Eu sou diretor".

As mudanças de estrutura da atividade lúdica são representadas pelas ações da vida real e organizadas por um momento e papel representado (ROCHA, 2005). O fato de a criança assumir um papel diante uma atividade variada faz com que ela cada vez mais siga uma lógica da realidade. Isto acontece devido às habilidades e idades de cada indivíduo, sendo capaz de realizar diferentes funções na atividade lúdica proposta. Por outro lado, ainda Rocha (2005, p. 74) diz que:

[...] parece coexistir uma relação inversa, apontando para as influências que a presença de determinados objetos (mesmo que configurem apenas um pano de fundo na atividade) exercem sobre a possibilidade da criança assumir um papel e imaginar uma temática.

Aqui a autora aponta a imaginação como uma influência aos papéis e que as crianças ao jogar simbolicamente assumem um papel imaginado por elas de acordo com o "cenário temático", deixando de lado suas habilidades desenvolvidas, facilitando o processo para assumir este papel, que, desempenhados de forma gradativa podem assumir um espaço principal da estrutura do jogo e se transformam, de mais 
generalizados para mais tipificados, específicos, para o surgimento de temáticas orientadoras do jogo (ROCHA, 2005).

No outro dia, a atividade foi o futebol. Participaram 20 a 25 crianças entre 06 a 14 anos, meninos e meninas que jogaram juntos, sem distinção de gênero. $O$ interessante nesta atividade foi o sentido cooperativo entre os participantes de diferentes idades que se respeitavam por suas diferenças. Ao iniciar o jogo novamente foi evidente o aspecto simbólico do jogo, pois os jogadores se sentiam profissionais, afirmando:

- "Nós somos a França, eu sou Zidane, eu sou Henry".

O jogo simbólico mais uma vez se fez presente nas atividades de lazer em hotelaria, possibilitando o desenvolvimento da imaginação e da criatividade, estabelecendo um sentido educativo e pedagógico no processo das atividades e pessoas envolvidas (ROCHA, 2005).

Durante o jogo as crianças menores, ao receberem a bola não eram abordadas pelos marcadores que permitiam com que eles tocassem a bola para outra pessoa, dando sequência ao jogo. De acordo com a pedagogia do esporte isso fez com que o jogo fosse possível naquele momento, pois promoveu a participação de todos e o ambiente foi repleto de possibilidades e potenciais pedagógicos (VENDITTI e SOUSA, 2008; PAES, 2002).

Embora o futebol seja culturalmente competitivo, apresentou uma dimensão cooperativa marcada pela amizade entre todos e pela preocupação em não prejudicar o adversário e não correr riscos quando estava caracterizada uma diferença de tamanho, força ou habilidade, mesmo com a competição presente (BROTTO, 2002).

Além de todas as características educativas citadas, respeito ao próximo, às regras, às emoções, ao simbolismo e a integração dos participantes, evidenciou-se 
desenvolvimento dos aspectos cognitivo e motor, e a relação entre ambos, uma vez que as crianças após uma ação não satisfatória discutiam sobre e desempenhavam uma nova estratégia de jogo. Uma das crianças no meio do jogo notou uma deficiência estratégica em seu time e rapidamente reúne seus jogadores para discutirem uma estratégia, então se ouviu:

- Fica você aqui, você ali e o outro atrás, assim fíca mais difícil de queimar a gente".

A possibilidade de elaboração de estratégias naquele momento do jogo pode ser vista como uma situação que envolveu o "pensar fora do objeto de jogo". Quando uma estratégia não dava certo o jogo era interrompido pelas crianças que pensavam e repensavam, criando adaptações às estratégias para a execução de uma nova tática, propondo uma resolução dos problemas identificados no jogo (BROTTO, 2002; PIAGET, 1975).

Foi estabelecida uma nova regra, permitindo "queimar" os adversários também pelas laterais da quadra e não apenas do fundo dela ou do lado de dentro do espaço válido. A ideia foi aceita por todos, pois uma ação nova atua como fator motivacional e cultural, à medida que a variação da atividade fez com que algumas crianças que não conheciam a brincadeira questionassem.

- “Como é essa brincadeira?".

- "Vem cá, eu te ensino!".

Neste momento, a atividade é caracterizada pela aprendizagem cultural, pois a criança não conhecia a brincadeira, onde o objetivo era o mesmo, com características culturais diferentes, uma vez que esta variação nunca ocorreu em seu meio social. Dá-se a importância da diversidade cultural no ambiente não formal, sendo que na hotelaria 
pessoas de todas as partes se relacionam e trocam experiências e conhecimentos, bem como, o aspecto social e integrativo do contexto, o que fez uma criança ajudar a outra. (BRASIL, 1997).

A atividade seguinte chamada de "Mãe da música" foi realizada na piscina, proposta pela equipe de lazer. O monitor da empresa de recreação posicionou-se na parte rasa da piscina e os participantes ficaram dispostos de um lado da borda. $\mathrm{O}$ objetivo da brincadeira era atravessar de lado cantando uma música com uma palavra qualquer escolhida pelo pegador, que estaria no meio da piscina. Quando o pegador, inicialmente o monitor da recreação escolhia uma palavra, todos deveriam cantar uma música com a palavra, se soubessem trocavam de lado da piscina sem problemas, porque não podiam ser pegos, já, se não sabiam deveriam passar sem que o monitor pegasse.

Do ponto de vista motor as crianças realizaram diferentes ações motoras dentro da água, utilizando várias formas de nadar. Ao saltar, andar e nadar as crianças dentro da água experimentaram diferentes resistências do meio líquido, em relação às brincadeiras fora da piscina. Algumas crianças menores foram, mais uma vez, ajudadas pelas crianças maiores, adotando um sentido cooperativo à atividade.

A diversidade cultural do grupo ficou intensa durante esta atividade, pois muitas crianças cantavam músicas que outras não conheciam. Por vezes ouviu-se:

- "Que música é essa, não conheço".

- “Ah! É lá da minha cidade, de uma banda de lá!”.

A diversidade possibilitou aos indivíduos o conhecimento de diferentes aspectos culturais de outros grupos sociais, fazendo com que a partir daquele momento as 
crianças que não conheciam certa música, se familiarizassem com um novo ritmo musical. Esta atividade teve um tempo de quarenta minutos.

No terceiro dia de recreação acompanhou-se um jogo de mesa, o pingue-pongue. As crianças já se encontravam com um grau de intimidade maior devido ao tempo de convivência. Falava de suas cidades, o que faziam sobre o que gostavam de fazer, onde estudavam, combinavam encontros, etc. Em meio a este jogo, um garoto novo que acabara de chegar disse ser de outro estado. Quando chegou sua vez de jogar, ele não entendia como a maioria jogava e dizia que aquilo era muito rápido e não estava certo. Ele questionou a maneira da pontuação do saque, pois para a maioria, tal fundamento errado era ponto para o adversário, e ele entendia que no saque não seria ponto direto e sim vantagem seguida de ponto. Todos ficaram surpresos com uma regra diferente:

- "Nossa que estranho!".

Ele respondeu:

- "Na minha cidade sempre jogamos assim".

Depois de uma hora notou-se a importância, mais uma vez de esclarecer a diversidade cultural existente entre hóspedes de um hotel, pois as pessoas envolvidas trocam experiências e vivências de diferentes culturas, de várias práticas sociais. É bem visível neste jogo de pingue pongue que as regras de uma cultura podem ser diferentes de outra, fazendo com que os indivíduos aprendam novas formas e vivenciem outras culturas durante uma atividade hoteleira (BRASIL, 1997). Entende-se que o profissional da recreação em suas atividades conseguiu possibilitar a integração entre essas culturas, não somente entre as crianças, mas entre as diversas faixas etárias, havendo uma aprendizagem compartilhada de quem participa e de quem as estimula também. 


\section{Categorias de Análise}

\section{Cultura Corporal do Movimento}

A sociedade abrange em sua totalidade diferentes contextos e culturas individualizadas a cada território e a cada indivíduo em seus aspectos psicológicos, intelectuais e conhecimentos adquiridos através de experiências durante sua vida. A diversidade cultural acontece por meio das interações sociais, valores, saberes, corrente das práticas cognitivas e motoras realizadas em situações ocorridas em sociedade. $\mathrm{O}$ grande desafio é conhecer e desenvolver a riqueza representada pela diversidade cultural que compõe um patrimônio sociocultural, valorizando os diferentes grupos compostos em diversas sociedades.

A diversidade cultural ou pluralidade cultural proposta pelos Parâmetros Curriculares Nacionais (1997) é um tema transversal para educação, enfatizando as diversas heranças culturais de uma sociedade, uma vez que existe a necessidade social de se vivenciar toda a pluralidade das diferentes culturas existentes. Sobretudo é importante enfatizar que cabe aos educadores transmitir este conhecimento plural e cultural a seus educandos. Novamente abrimos mão dos Parâmetros Curriculares Nacionais:

Pluralidade cultural quer dizer a afirmação da diversidade como traço fundamental na construção de uma identidade nacional que se opõe e repõe permanentemente, e o fato de que a humanidade de todos se manifesta em forma concretas e diversas de ser humano (1997, p. 19).

É desta forma que a pluralidade cultural acontece e que através de diferentes situações e contexto social ela é educativa, fazendo parte de um processo de ensino e aprendizagem, seja na educação formal ou não formal. Essa ação cultural, ou seja, a exposição de diferentes culturas é evidente na hotelaria, pois, pessoas de diferentes sociedades se encontram e trocam experiências culturais através de conversas, troca de 
ideias e por meio das atividades de lazer e recreação, onde diferentes expressões culturais acontecem.

Durante a análise das atividades a pluralidade foi identificada através de diferentes formas, movimentos, músicas e regras, que em certa região do país uma simples regra de pingue pongue, explícita por um garoto era diferente. No momento em que o garoto expôs sua forma de jogar os demais estranharam - "Na minha cidade sempre jogamos assim!”, ele respondeu. A pluralidade aqui é demonstrada através das regras de um jogo de pingue pongue e que mesmo com regras instituídas por uma federação sofre alterações de acordo com uma cultura. Esse fato e outros quando as crianças na piscina cantavam uma delas com um ritmo diferente apresentou uma música e movimentos, até o momento desconhecido, foi quando novos questionamentos surgiram devido à nova forma cultural exposta. Daolio (1995, p. 36) em seu estudo da cultura do corpo ressalta que;

É a partir da concepção de que o homem possui uma natureza cultural e de que ele se apresenta em situações sociais específicas de que se chega a ideia de que o que caracteriza o ser humano é justamente sua capacidade de singularização por meio da construção social de diferentes padrões culturais.

O autor enfatiza a relação das diferentes culturas e situações sociais com a capacidade do homem de construir ações a partir de diferentes padrões de movimentos, podendo demonstrar isso através de sua corporeidade. Assim, é possível discutir o corpo como uma construção cultural, pois cada sociedade se expressa por meio de corpos diferentes e mesmo inconsciente deste processo, cada indivíduo possui sua especificidade cultural. (DAOLIO, 1995).

O homem é configurado pela sociedade com alguns atributos de normas sociais a serem respeitadas, seja do ponto de vista intelectual, moral ou físico e que por meio de 
seu corpo, o homem se apropria dos valores e costumes sociais. Por isso, Daolio (1995, p. 39) em suas palavras diz que: "No corpo estão inscritos todas as regras, todas as normas e todos os valores de uma sociedade específica, por ele ser o meio de contato primário do indivíduo com o ambiente que o cerca." Desta forma o autor relaciona a especificidade de cada cultura junto à corporeidade de cada indivíduo e que o corpo representa toda a forma cultural, seja por gestos, forma de andar, ou postura corporal. Estes aspectos culturais, desenvolvidos através da diversidade cultural são evidentes na análise realizada no hotel.

Para Gonçalves (1994, p.13)

[...] as concepções que o homem desenvolve a respeito de sua corporalidade e as suas formas de comportar-se corporalmente estão ligados aos condicionamentos sociais e culturais. A cultura imprime suas marcas no indivíduo, ditando normas e fixando ideais na dimensão intelectual, afetiva, moral e física, ideais esse que indicam à Educação o que deve ser alcançado no processo de socialização.

A autora aborda a corporeidade como o corpo de cada indivíduo inserido em um determinado grupo social expressando a história de uma sociedade, marcada por seus aspectos de valores, leis, crenças e sentimentos de uma vida social. Os indivíduos em análise desempenharam através de músicas, regras e movimentos toda sua corporeidade e expressão corporal, fazendo com que todos vivenciassem novas culturas, e que por meio de questionamentos e ações cognitivas pensaram a respeito, havendo uma cumplicidade e respeito cultural. Isto aconteceu durante as atividades de lazer e recreação, proporcionando as crianças estas especificidades culturais e sua diversidade, aproximando, assim, um sentido educativo destas atividades desenvolvidas no contexto não formal, no hotel. 


\section{Jogo Simbólico e Ação Cognitiva}

A atividade simbólica é desenvolvida no hotel em diferentes momentos e situações decorrentes das atividades de lazer e recreação, sendo responsável por várias interpretações, sejam elas culturais reais ou imaginárias desenvolvidas cognitivamente em um processo adaptável em sua prática. No hotel, um ambiente não formal, o jogo do faz-de-conta acontece de muitas maneiras e cenários elaborados pelos monitores. Desde a chegada das crianças, pelo menos um dos profissionais da recreação esteve sempre fantasiado para recepcioná-los, de maneira lúdica.

Autores como Freire (1997) e Rocha (2005), em seus trabalhos abordam a imaginação junto ao jogo do faz-de-conta, coexistindo uma ação mental para o desenvolvimento cognitivo. Magill (2000) faz referência à prática cognitiva junto à capacidade imaginária, atribuindo estes aspectos ao ato motor. O jogo simbólico representa uma assimilação no e do pensamento, de forma livre para agir com a realidade e a fantasia do próprio eu. O desenvolvimento cognitivo na ação do jogo deixa evidente na intervenção do monitor, a aproximação do real ao imaginário, onde o ser humano retoma o caminho para si mesmo, se opondo ao mundo objetivo, retomando ao caminho para liberdade. (PIAGET 1975; FREIRE, 1997).

Por meio do jogo simbólico a criança demonstra o desenvolvimento do aspecto cognitivo, penetrando em um mundo extremamente diferente, onde se envolve no mundo da magia, do faz-de-conta, transformando simples objetos e situações em grandes contextos da fantasia. Diante das atividades analisadas houve ocasiões onde as crianças fantasiaram personagens, vivenciando em suas imaginações momentos de representações de imagens simbólicas. Uma das atividades analisadas abordou este 
assunto, onde o jogo do faz-de-conta fez-se presente quando as crianças participavam de um simples futebol.

"Nós somos a França, eu sou Zidane, eu sou Henry". Esta situação de faz-deconta acontece durante toda atividade, sobretudo, acontece devido aos personagens imaginados serem famosos futebolistas. A associação aos astros do futebol é um fator determinante do desenvolvimento cognitivo, porque, ao imaginar estes jogadores, em realidade, as crianças sabem quem é e o porquê é grandes jogadores, nenhuma das crianças se imaginou naquele momento, jogadores de um time ou seleção que não fosse mundialmente famosa (PIAGET, 1975). É neste sentido que o jogo do faz-de-conta associa-se a realidade e em sua importância a ação cognitiva faz com que a fantasia desenvolvida seja mais próxima do real, saber em quem imaginar.

A inteligência da criança se mostra na construção do raciocínio lógico e coerente diante dos problemas tornados gradativamente compatíveis com a realidade. Essa adaptação do mundo seja física ou mental é inferido no desenvolvimento cognitivo, nas ações da vida das pessoas em suas experiências, através do faz-de-conta ou por meio da realidade social em que o indivíduo vive. Esta associação acontece como uma regra, permeada pelo jogo de regra (PIAGET, 1975; VIGOSTSKY, 2001; WALLON, 1989).

A relação entre o jogo do faz-de-conta e o jogo de regras é vista no estudo de Rocha (2005) como um "eixo evolutivo", indicando o jogo de regras e imaginário como categorias fundamentais, participando de uma forma e outra de jogo. Vygotsky (2001) salienta que as regras e imaginário são "elementos chaves" que durante o desenvolvimento acontece uma predominância invertida e a evidência de uma ou outra categoria. No jogo do faz de conta às regras são ocultas e somente através de análises são reconhecidas e identificadas, diferentemente do imaginário que se sobressai, 
fazendo com que este pareça o único processo psicológico caracterizado na atividade. Na coleta feita no hotel, para obtenção deste estudo, a relação entre estes jogos ocorre em uma das atividades, onde as crianças escolhem seus papéis estabelecendo as regras dos personagens escolhidos.

- “Eu faço as maquiagens", "Eu sou diretor”. Assim, o jogo de regra e o jogo do faz-de-conta estão presentes quando os sujeitos escolhem o personagem, imitando-os de acordo com suas funções. Cada figura realiza suas próprias funções sem interceder em outra, esta seria a regra estabelecida no momento. Aqui através do jogo simbólico, do faz-de-conta, desenvolve aspectos cognitivos através de representações mentais inteligíveis de cada criança, relacionando todas estas variáveis simbólicas e de encantamento ao interesse artístico do lazer, descrito por Marcellino (2002).

A imaginação apresentada pelas crianças enquanto jogavam teve uma atenção especial. Através da situação dos jogos simbólicos, muitos momentos foram relevantes para a aprendizagem, fazendo com que as crianças assumissem papéis importantes enquanto jogadoras, ativando de forma simbólica o desenvolvimento cognitivo da criança. A distorção da realidade foi representada pelos jogos propostos e seus "cenários temáticos" conforme orientação recebida. (ROCHA, 2005).

\section{A Competição como Sociabilização}

A questão da competição é considerada muitas vezes como um fator negativo, à medida que o homem negue este processo intrínseco de si mesmo. O jogo e o esporte em seu contexto lúdico representam ações individuais e coletivas das pessoas e da sociedade (FREIRE, 1997). É visto que competição é representada pelo jogo e não originada por ele e, as ações emotivas instauradas pelos competidores são inerentes de 
sua própria índole. Huizinga (1999), afirma que a competição é parte do jogo e não há razão alguma para recusá-la, pois possui características formais e funcionais do jogo, assim como a característica lúdica desenvolvida por ele. Desta forma a competição é consequência da vida das pessoas, e quando desenvolvida de forma educativa pode promover um processo de aprendizagem, devido às regras e motivação, por exemplo.

De acordo com Kamii (1991): "O aspecto competitivo do jogo pode contribuir para o desenvolvimento da criança porque o jogo requer elaboração e cumprimento de regras.” (p. 281). A autora em sua afirmação fala da competição como um fato importante para a sociedade, pois a elaboração e o respeito às regras são fatores de um sistema social de cada indivíduo e já que os jogos de competição requerem regras, surgem oportunidades especiais para o envolvimento das crianças em sua elaboração. Existe, no momento de acatamento e elaboração de regras, um processo construtivo de importância para as crianças, pois as tornam indivíduos capazes de desenvolver o senso de justiça, estabelecendo valores sociais. (KAMII, 1991).

No estudo de Kamii (1991) a evidência do aspecto competitivo do jogo é dada também pela regra, o que expõe ainda mais a importância da competição. Durante o desenvolvimento e análise deste estudo, notou-se esta questão da regra como um aspecto importante em relação à elaboração e papéis desenvolvidos pelas crianças enquanto jogavam. Além deste aspecto, outro relevante foi identificado, onde as crianças em competição sociabilizavam-se com outras pessoas desconhecidas realizando um novo processo de aprendizagem, competição para sociabilização. Esta aprendizagem pôde ser possível devido à regra do jogo anteriormente estabelecida pelo monitor da recreação, bem como, ressaltar que sua ludicidade é um traço predominante para a questão educativa. 
O aspecto competitivo das atividades de lazer e recreação aplicada em hotéis possui traços também positivos e educativos, sobretudo, independente de onde é desenvolvida, seja em ambiente formal, como escolas e em contextos não formais, como hotéis, é preciso ater-se de como a competição será proposta. Na análise realizada através da coleta de dados deste estudo, percebeu-se que o monitor recreador aplicou a competição com o intuito de promover a sociabilização das pessoas envolvidas e que em sua prática esta situação aconteceu. As crianças deixaram suas inibições de lado e conheceram novas pessoas em busca de uma determinada resposta para suas questões.

Dentro de uma proposta da educação integral do indivíduo, diferentes aspectos pedagógicos foram atribuídos através das atividades de lazer e recreação realizadas em hotéis. As regras e a sociabilização identificadas em análise são características educativas de um processo competitivo, uma vez que esta proposta é capaz de incentivar o desenvolvimento social, moral, emocional, cognitivo e motor dos sujeitos inseridos no contexto. A sociabilização durante todo o tempo de estada dos indivíduos ocorreu de diferentes maneiras, através de conversas, brincadeiras e jogos, bem como, em uma situação interessante, onde a competição fez com que este processo acontecesse.

\section{Educação Não Formal e Potencial Motor}

De acordo com Gallahue e Ozmun (2003), a herança genética é responsável pela individualidade de cada pessoa, uma vez que esta individualidade é também responsável pela similaridade, vista como uma tendência do desenvolvimento humano que acontece de maneira ordenada e previsível. Os fatores biológicos que afetam o desenvolvimento motor surgem de um padrão previsível de movimentos. É claro que além das particularidades genéticas, os padrões possíveis de movimento são aqueles que 
acontecem referidos ao nível de maturação e que são afetados pelo meio e experiências de cada sujeito. "Tanto o processo quanto o produto do movimento de um indivíduo estão enraizados em um ambiente experimental e genético peculiar, conectados às exigências específicas da tarefa motora" (GALLAHUE e OZMUN, 2003, p. 61). Essas exigências da tarefa motora ocorrem devido às situações, sejam culturais, sociais ou maturacionais em que o sujeito se encontra para a realização de seus movimentos.

Freire (1997) propõe aponta a não padronização dos movimentos humanos, pois para isso o mundo também deveria ser também padronizado. $\mathrm{O}$ autor cita a importância de esquemas motores dizendo que são: “[...] organizações de movimentos construídos pelos sujeitos, em cada situação, construções essas que dependem, tanto dos recursos biológicos e psicológicos de cada pessoa, quando das condições do meio ambiente em que ela vive.” (p. 22). O desenvolvimento motor acontece de diferentes maneiras que não unicamente pelo padrão de movimento, pois cada situação vivenciada no ambiente os indivíduos adaptam seus movimentos à realidade experimentada (FREIRE, 1997).

No diário de campo diversas situações e movimentos realizados pelas crianças foram evidenciadas através das brincadeiras e jogos de origem simbólica, cultural, de regras e exercícios. Múltiplos movimentos caracterizados por crianças de diferentes idades aconteceram, deixando de lado os padrões de movimento, devido à diversidade de habilidades expostas por diferentes indivíduos, respeitando, é claro, o nível de maturação de cada criança. As atividades lúdicas proporcionaram às crianças realizarem ações motoras em diferentes graus de ambientações e em quadra, as crianças realizaram suas habilidades motoras básicas, como correr, saltar, girar entre outros.

As atividades lúdicas propostas terem proporcionado às crianças ações motoras em diferentes graus de diversidade e complexidade. Por esse motivo, o objetivo dessa 
categoria não é apresentar uma avaliação ou demonstrar um aprimoramento ou desenvolvimento motor dos sujeitos durante três dias de análise, mas corroborar que com as atividades executadas num contexto educacional não formal, como o hotel, seja possível possibilitar diversas ações motoras para que o processo de desenvolvimento continue ao longo do período de férias. Tani (2006), nesse âmbito descreve que o desenvolvimento ótimo do potencial motor de crianças e a melhora na sua capacidade de se movimentar possibilita a elas interagirem de maneira harmoniosa e eficiente com o meio lúdico, social e cultural com que vivem. Como demonstrou a análise da atividade quando uma criança, respeitando a condição da outra, pôde ajuda-la.

- “Como é essa brincadeira?".

- "Vem cá, eu te ensino!".

Além de a Educação Física escolar ter a responsabilidade de desenvolver, aprimorar e a possibilitar a criança experiências motoras, objetivando a ampliação e enriquecimento do seu repertório motor poderia caber ao monitor de lazer e recreação, aos agentes da educação não formal, contribuir nessa questão motora. Pois, mesmo o grupo e o nível de movimentos e formas motoras sendo heterogêneas, as atividades propostas pela programação de lazer foram possíveis e contribuíram motoramente a todos. A relação entre a diversidade cultural e o corpo em movimento, demonstrou um formato diferente de se movimentar, ou seja, por muitas vezes esse processo aconteceu devido a uma musica ou jogo expresso por uma cultura específica. O que deixa ainda mais rico o repertório motor da criança. 


\section{Considerações Finais}

Este estudo objetivou demonstrar que as atividades de lazer e recreação realizadas em hotéis possuem características educativas, mesmo desenvolvidas em um contexto não formal. Existe uma educação não formal que proporciona um processo de aprendizagem sistematizada e programada, como são as atividades de lazer em hotéis. Os autores descritos neste trabalho Marcellino (2002), Camargo (1992) e Waichman (1997) compreendem um processo educativo do lazer e recreação, podendo esta temática proporcionar uma aprendizagem lúdica em diferentes contextos em que é desenvolvida. Pelo potencial de aprendizagem sociocultural, cognitiva, afetiva, de sociabilização e de uma variedade de ações motoras, notou-se que a hotelaria preocupase em atender seus clientes, bem como a empresa de recreação e lazer e seus profissionais em atender os seus, os hotéis.

É visto que muitos profissionais da recreação e lazer possuem diferentes formações e que mesmo assim preocupam-se em satisfazer os hóspedes. Em busca do objetivo educativo, a investigação construída foi de extrema valia, pois contribuiu em identificar diferentes características pedagógicas nas atividades desenvolvidas, o que concretizou a realização de análises das categorias escolhidas, (1) cultura corporal do movimento; (2) jogo simbólico e ação cognitiva; (3) a competição como sociabilização; (4) educação não formal e o potencial motor. Estas categorias de análise demonstraram que as atividades de lazer e recreação desenvolvidas em hotéis possuem então características educativas, pois através da diversidade cultural e corporeidade foi possível perceber a importância das diferentes pessoas e suas especificidades cognitivas, culturais e corporais como estudado por Daolio (1995). Com o jogo simbólico foi possível demonstrar a importância da ação cognitiva das crianças, uma vez que estas, 
através da imaginação desempenharam um papel autônomo e inteligente (VYGOTSKY, 2001).

A questão da competição como veiculo da sociabilização, houve um fato positivo, pois através da competição as crianças respeitaram as regras e socializaram-se com outras pessoas que não conheciam, fazendo com que toda inibição por parte das crianças fosse esquecida. A elaboração e o cumprimento das regras caracterizam o processo educativo das crianças, pois estão em questionamento, sendo criticas e seguindo os valores éticos de competir. (KAMII, 1991). Sobre o corpo em movimento, na categoria de desenvolvimento motor, diferentes ações motoras e múltiplos movimentos foram identificados através de padrões motores e a "quebra" destes padrões, uma vez que algumas crianças realizaram movimentos diferentes do padrão descrito por Gallahue e Ozmun (2003) em seu estudo.

Assim, com todas estas evidências e atribuições descritas neste estudo acreditase que as atividades de lazer e recreação realizadas em ambiente não formal, aqui demonstrado pelo hotel, possuem características educativas e que estas complementam a educação formal escolar, demonstrando que na área não formal existe um processo de educação complementar a partir das atividades de lazer e recreação realizadas em hotéis, sendo parte da educação fundamental e integral dos indivíduos inseridos na não formalidade chamada então educacional. Portanto, é visto que as atividades realizadas em hotéis em programação de lazer possuem características educativas, no entanto, não são avaliadas como deveriam e que muitas vezes isto acontece devido ao sistema padronizado das empresas prestadoras de serviço, que objetivam a satisfação dos hóspedes, mas não possuem um sistema de avaliação para propostas e ações educacionais. Essa seria uma perspectiva de atuação ao profissional de recreação e 
lazer, as empresas podem oferecer subsídios com propostas de atividades e avaliações que promovam ações educativas. Posteriores estudos com intuito de analisar parâmetros educacionais em diferentes faixas-etárias e suas específicas programações de lazer em adultos pode ser desenvolvidos.

\section{REFERÊNCIAS}

BRASIL. Ministério da Educação e do Desporto. Secretaria de Educação Fundamental. Parâmetros curriculares nacionais: apresentação dos temas transversais e pluralidade cultural. Brasília: Ministério da Educação e do Desporto, 1997.

BROTTO, F. O. Jogos Cooperativos: O jogo e o esporte como um exercício de convivência. Santos: Projeto Cooperação, 2002.

BREMBECK, C.S. Formal education, non-formal education, and expanded conceptions of development: occasional papers non formal education. Michigan: Institute for International Studies in Education, 1978.

CAVALLARI, V. C.; ZACHARIAS, V. Trabalhando com recreação. 8. ed. Atual. São Paulo: Ícone, 2005.

CAMARGO, L, O. O que é lazer. 3. ed. São Paulo: Brasiliense, 1992.

Educação para o lazer. São Paulo: Modena, 1998.

COOMBS, P. H.; PROSSER, R., M. Ahmed. New paths to learning for rural children and youth. New York: International Council for Education Development, 1973.

DAOLIO, J. Da cultura do corpo. Campinas: Papirus, 1995.

DUMAZEDIER, J. Valores e conteúdos culturais do lazer. São Paulo: SESC, 1980.

DUMAZEDIER, Joffre. Lazer e cultura popular. São Paulo: Perspectiva, 1976.

FERREIRA, V. Educação Física, recreação, jogos e desportos. Rio de Janeiro: Sprint, 2003.

FIORENTINI, D. Investigação em educação matemática: percursos teóricos $\mathrm{e}$ metodológicos. Autores Associados: Campinas, 2006.

FIORENTINI, D.; LORENZATO, S. Investigação em Educação Matemática: percursos teóricos e metodológicos. Campinas: Autores Associados, 2006. 226 p. 
FREIRE, J. B. Educação de corpo inteiro: Teoria e prática da educação física. 4. ed. São Paulo: Scipione, 1997.

GAllahuE, D. L.; OZMUN, J. C. Compreendendo o desenvolvimento motor: bebês, crianças, adolescentes e adultos. São Paulo: Ed. Phorte, 2003.

GONÇALVES, M. A. S. Sentir, pensar, agir - Corporeidade e educação. Campinas: Papirus, 1994.

GOMES, C. L. Dicionário critico do lazer. Belo Horizonte: Autentica, 2004.

HUIZINGA, J. Homo ludens: o jogo como elemento da cultura. Perspectiva: São Paulo, 1999.

KAMII, C. Jogos em grupo na Educação Infantil: Implicações da teoria de Piaget. São Paulo: Trajetória Cultural, 1991.

LÜDKE, M. e A., M. Pesquisa em educação: abordagens qualitativas. São Paulo: EPU, 1986.

MAANEN, V. J. Reclaiming qualitative methods for organizational research: a preface. Administrative Quaterly Science, 1979. p. 520-526.

MAGILL, Richard A. Aprendizagem motora: conceitos e aplicações. São Paulo: Edgard Blücher, 2000.

MARCELlinO, N. C. Estudos do Lazer: Uma introdução. 3. ed. Campinas: Autores Associados, 2002.

Lazer e Educação. Campinas: Papirus, 1987.

NEGRINE, A.; BRADCZ, L.; CARVALHO. Recreação na Hotelaria: o pensar e o fazer lúdico. Caxias do Sul: EDUCS, 2001.

PARÂMETROS CURRICULARES NACIONAIS. Pluralidade cultural, orientação sexual / Secretaria da educação Fundamental. Brasília: MEC/SEF, 1997.

PAULSTON, R. G. Non-Formal Education. An Annotated International Bibliography. New York / London: Praeger Publishers, 1972.

PAES, R. R. Pedagogia do esporte e os jogos coletivos. In: DE ROSE Jr., Dante. Esporte e atividade física na infância e na adolescência. Porto Alegre: Artmed, 2002.

PIAGET, J. A formação do símbolo na criança: imitação, jogo, sonho e representação. Rio de Janeiro: Zahar, 1975. 
ROCHA, M. S. P. DE MOURA. L. DA, Não brinco mais: a (des) construção do brincar no cotidiano educacional. 2. ed, Ijuí: Ed. Unijui, 2005.

REQUIXA, R. O lazer no Brasil. São Paulo: Brasiliense, 1977.

As Dimensões do Lazer. São Paulo: SESC / Celazer, 1974.

REQUIXA, R. Sugestões de diretrizes para uma política nacional de lazer. São Paulo: SESC/ Celazer, 1980.

TANI, G. Comportamento motor e sua relação com a educação física. Brazilian Journal of Motor Behavior, 2006.

THOMAS, J. R.; NELSON, J. K. Métodos de pesquisa em atividade física. 3. ed. Porto Alegre: Artmed, 2002.

VENDITTI, R. Jr.; SOUSA, A. M. Tornando o jogo possível: reflexões sobre a pedagogia do esporte, os fundamentos dos jogos desportivos coletivos e a aprendizagem esportiva. Revista Pensar a Prática, jul. 2008.

VYGOTSKY, L. S. A construção do pensamento e da linguagem. São Paulo: Martins Fontes, 2001.

WAICHMAN, P. Tempo livre e recreação: Um desafio pedagógico. Campinas: Papirus, 1997 (Coleção Fazer/Lazer).

WALLON, H. As origens do pensamento na criança. São Paulo: Manole, 1989.

WERNECK, C. L.G.; ISAYAMA, H. F. Lazer. Recreação e educação física. Belo Horizonte: Autentica, 2003.

.; STOPPA, E. S.; ISAYAMA, H. F. Lazer. Recreação e educação física. Belo Horizonte: Autentica 2003.

\section{Endereço dos Autores:}

Marcio Aparecido F. de Godoy Fazolin

Rua Dr. Alves do Banho, 796, apartamento 146, torre 3

Campinas - SP - 13.030-580

Endereço Eletrônico: mafazolin@gmail.com

Luciano Allegretti Mercadante

Rua vicenzo trevisan 257

Itatiba - SP - 13.254624

Endereço Eletrônico: lucianomerc@yahoo.com.br

Regina Célia Grando

Rua vicenzo trevisan 257 
Marcio Aparecido F. de Godoy Fazolin,

Luciano Allegretti Mercadante e Regina Célia Grando

Itatiba - SP - 13.254624

Endereço Eletrônico: regrando@yahoo.com.br 